\title{
A Rare Cause of Cholestasis Related to Polycystic Liver Disease
}

\author{
Pedro Costa-Moreira ${ }^{a, b}$ Susana Lopes ${ }^{a, b}$ Guilherme Macedo ${ }^{a, b}$ \\ ${ }^{a}$ Gastroenterology Department, Centro Hospitalar Universitário São João, Porto, Portugal; ${ }^{b}$ Faculty of Medicine, \\ University of Porto, Porto, Portugal
}

Keywords

Polycystic liver disease · Vascular liver disease $\cdot$ Cholestasis

\section{Uma causa rara de colestase relacionada com doença hepática poliquística}

\section{Palavras Chave}

Doença hepática poliquística - Doença vascular hepática . Colestase

A 52-year-old female with autosomal dominant polycystic kidney disease (ADPKD) associated with polycystic liver disease (PLD) was referred to the gastroenterology clinic due to abnormal liver function tests. Laboratory testing demonstrated increased $\gamma$-glutamyltransferase $(1,231$ vs. normal $<40 \mathrm{IU} / \mathrm{L})$ and alkaline phosphatase ( 218 vs. normal <120 IU/L) levels. The patient was asymptomatic, and there were no clinical manifestations of portal hypertension. The etiological study for liver disease (including viral serologies, autoimmunity, iron kinetics, and ceruloplasmin) was negative. Abdominal magnetic resonance imaging (MRI) showed multiple hepatic cysts (the largest with a 13-cm diameter) (Fig. 1). Abdominal ultrasound with Doppler imaging showed a

karger@karger.com www.karger.com/pjg

Karger"

BOPEN ACCESS (c) 2021 Sociedade Portuguesa de Gastrenterologia. Published by S. Karger AG, Basel

This is an Open Access article licensed under the Creative Commons Attribution-NonCommercial-4.0 International License (CC BY-NC) (http://www.karger.com/Services/OpenAccessLicense), applicable to the online version of the article only. Usage and distribution for commercial purposes requires written permission. normal patency of the portal and hepatic veins (Fig. 2). A parenchymal liver biopsy showed marked centrilobular congestion with blood-filled cavities that resembled hepatic peliosis and was associated with findings of mild portal and intralobular inflammation (Fig. 3, 4).

After the diagnostic workup, we concluded that the patient had hepatic venous outflow obstruction secondary to cystic vascular compression. While the liver architecture is affected by PLD, the synthetic function of the polycystic liver remains intact until very late in the course of the disease $[1,2]$. Histological features of this functional disease include centrizonal congestion, necrosis, and hemorrhage. Large regenerative nodules, obstructive portal venopathy, and fibrosis/cirrhosis may also be found [3].

It is important to note that in the classical forms of peliosis hepatis, the lesions are randomly distributed in the liver parenchyma. However, in the case of vascular outflow obstruction, the sinusoidal dilation is more evident in the centrilobular area (zone 3) [4].

This case highlights a rare vascular liver disease related to a genetic condition that wouldn't usually have a significant impact on liver function. Early diagnosis may be helpful, allowing for a strategic cyst intervention that can avoid the consequences of portal hypertension. 


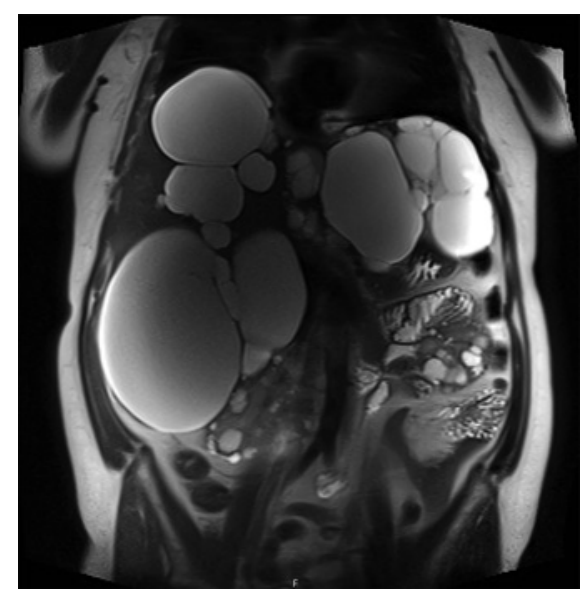

Fig. 1. MRI of large hepatic cysts distributed in the liver parenchyma.

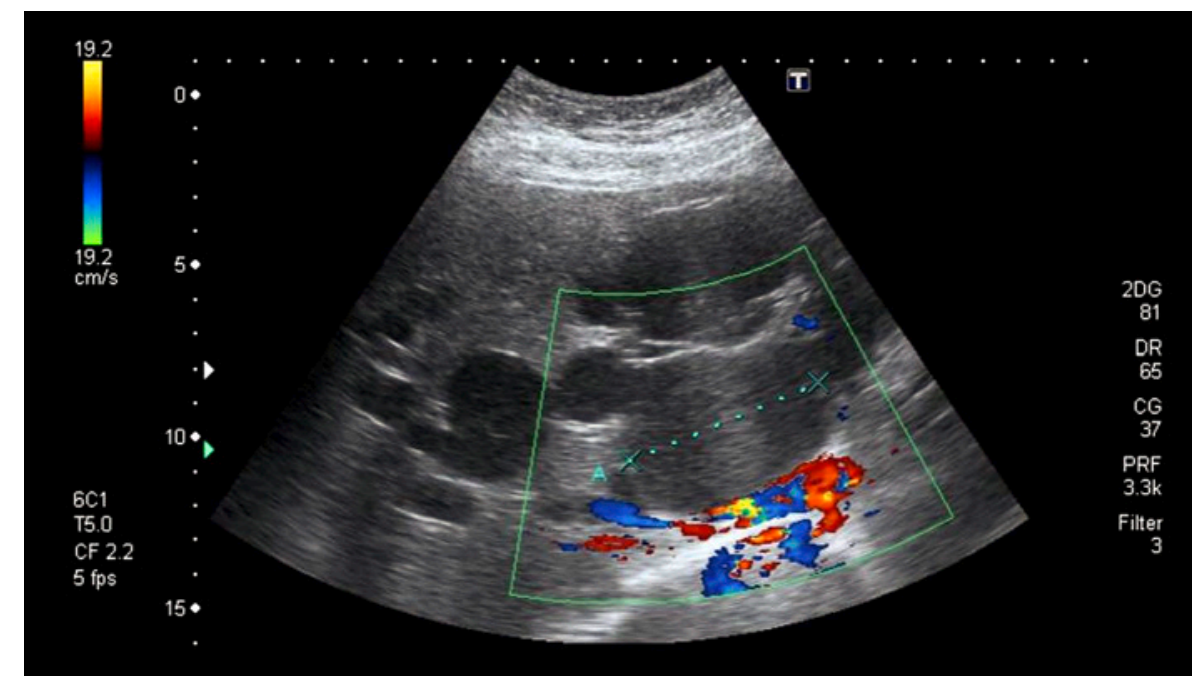

Fig. 2. Abdominal ultrasound with Doppler imaging of the portal vein. HE. $\times 100$.

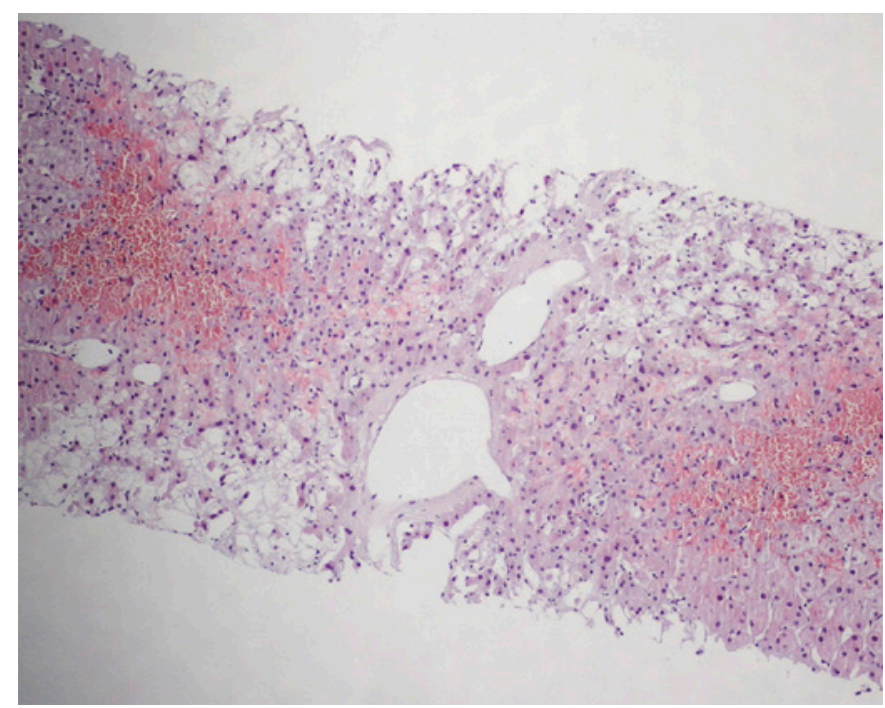

Fig. 3. Liver biopsy showing centrilobular congestion. HE. $\times 200$.

\section{Statement of Ethics}

The authors confirm that written informed consent was obtained for the publication of this case (including the images).

\section{Conflict of Interest Statement}

All authors disclosed that there are no personal conflicts of interest or financial relationships relevant to this publication.

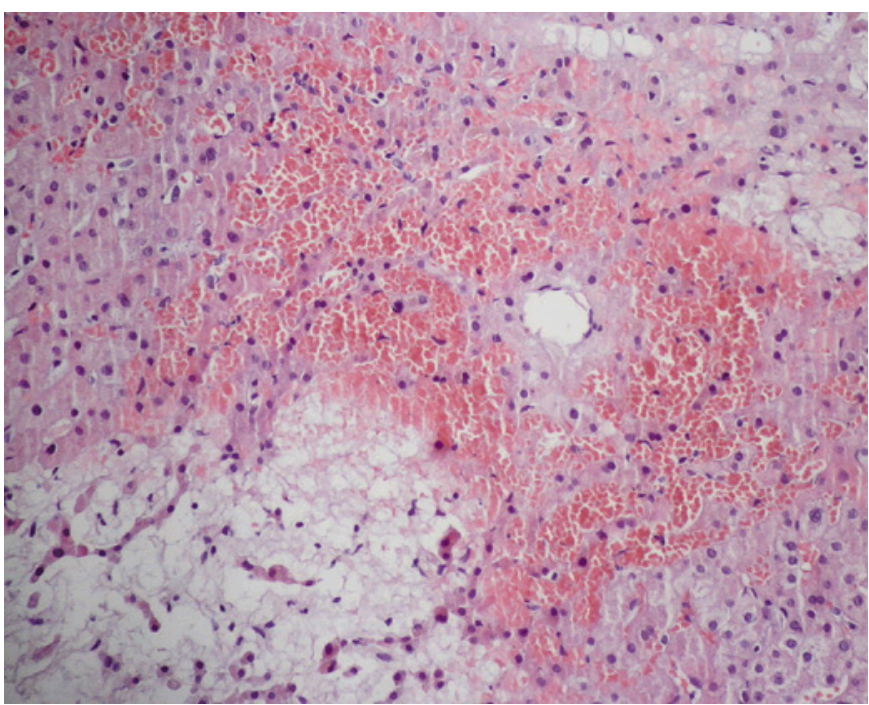

Fig. 4. Liver biopsy showing centrilobular congestion.

Funding Sources

There was no funding.

\section{Author Contributions}

P.C.-M.: manuscript concept and design, literature review, and draft of the manuscript. S.L. and G.M.: critical revision of the manuscript. All authors approved the final version. 
References
1 DeLeve LD, Valla DC, Garcia-Tsao G; American Association for the Study Liver Diseases. Vascular disorders of the liver. Hepatology. 2009 May;49(5):1729-64.

2 van Aerts RM, van de Laarschot LF, Banales JM, Drenth JP. Clinical management of polycystic liver disease. J Hepatol. 2018 Apr;68(4): 827-37.
3 Bernts LH, Drenth JP, Tjwa ET. Management of portal hypertension and ascites in polycystic liver disease. Liver Int. 2019 Nov;39(11): 2024-33.

4 Uddin W, Ramage JK, Portmann B, Wilson P, Benjamin I, Tan KC, et al. Hepatic venous outflow obstruction in patients with polycystic liver disease: pathogenesis and treatment. Gut. 1995 Jan;36(1):142-5. 